\title{
«HASTA LOS CONFINES DE LA TIERRA» (HCH 1,8): VOCACIÓN UNIVERSALISTA EN LA DOBLE OBRA LUCANA
}

Fecha de recepción: 12 de noviembre de 2018

Fecha de aceptación y versión final: 8 de enero de 2019

RESUMEN: El judaísmo basculó siempre entre el universalismo y el particularismo identitario. La fe cristiana superó desde el principio el particularismo judío. Todos los seres humanos están llamados a la fe y la Iglesia es católica, es decir, universal. Todos los escritos del N. T. son testigos de ello. La doble obra lucana no es una excepción. En el artículo, tras caracterizar literaria e históricamente los dos libros de Lucas, se pone de relieve el universalismo que se refleja en los aspectos étnicos, culturales y sociales, así como la atención de Lucas a la historia universal.

PALABRAS CLAVE: universalidad; judaísmo; historia; etnia; clase social; género.

\section{"To the Ends of the Earth" (Acts 1: 8): \\ Universalist Vocation in Luke-Acts}

ABSTRACT: Judaism always oscillated somewhere between universalism and self-defining particularism. The Christian faith broke away from Jewish particularism from the beginning. All human beings are called to faith and the Church is Catholic, in other words, universal. All writings of the New Testament substantiate this

Profesor Ordinario de Sagrada Escritura. Universidad Pontificia Comillas (Madrid): jrbusto@comillas.edu 
claim. Luke-Acts is no exception. After the literary and historical characterization of the two books of Luke, the article highlights the universalism displayed in ethnic, cultural and social aspects, as well as the focus that Luke places on universal history.

KEY WORDS: universalism; Judaism; history; ethnicity; social class; gender.

\section{INTRODUCCIÓN}

El judaísmo basculó siempre entre el universalismo y el particularismo identitario ${ }^{1}$. Si existe un único Dios, ha de ser Dios de todos los pueblos y su salvación ha de alcanzar a todos. Pero Israel es el pueblo elegido con el que Dios ha pactado una alianza, lo que le une a Él con una relación particular. La fe cristiana superó desde el principio el particularismo judío. Desde que san Pablo escribió en la Carta a los Gálatas $(3,28)$, el segundo escrito cristiano por su antigüedad, que precede en décadas a los evangelios canónicos y al que únicamente antecede en el tiempo la primera Carta a los Tesalonicenses: «No hay judío ni griego, esclavo ni libre, varón ni mujer, porque todos vosotros sois uno en Cristo Jesús», la fe y la religión cristiana son universales. Es decir, se dirige a todos los hombres a los que considera iguales ante Dios y, por tanto, también entre sí. La igualdad más radical entre los hombres nace de su vocación de hijos de Dios y de haber sido redimidos por Jesucristo. Esta igualdad radical es afirmada junto con las diferencias étnicas, sexuales, sociales y culturales inherentes a la naturaleza humana. Es cierto que entre los seguidores de Jesús de la primera hora hubo quienes pretendieron hacer compatible el particularismo judío con la fe cristiana pero esta postura no triunfó; por el contrario, lo que venció en la configuración apostólica de la fe fue el universalismo hasta el punto de que la catolicidad es una nota de todas las confesiones cristianas, como proclamamos en el Credo, y no solo de la Iglesia católica, de modo que entender la fe cristiana vinculada a límites étnicos, nacionales, de clase social o, por supuesto, de género o sexo ha de ser entendido como una tergiversación o adulteración de la misma fe. No ignoro que demasiadas veces en la historia la fe cristiana se ha vinculado con nacionalismos o

1 Cf. José Ramón Busto, "Rut y Jonás contra Esdras”, Sal Terrae 102, n. ${ }^{\circ} 12$ (2014): 653-664.

ESTUDIOS ECLESIÁSTICOS, vol. 94, núm. 369, junio 2019, 295-308, ISSN 0210-1610, ISSN-e 2605-5147 
particularismos de muy diverso tipo, pero esto solo significa que demasiadas veces los cristianos no han sido capaces de comprender y vivir su fe hasta sus últimas consecuencias.

Se me ha encargado que presente desde esta perspectiva de la universalidad la doble obra lucana -el tercer Evangelio y el libro de los Hechos de los Apóstoles-y, en consecuencia, lo primero que debo decir es que estos dos libros del Nuevo Testamento no son una excepción en este aspecto, sino que comparten con todos los demás la perspectiva universalista de la fe cristiana.

\section{ASPECTOS GENERALES DE LA DOBLE OBRA LUCANA ${ }^{2}$}

Hoy día hay consenso entre los estudiosos en que tanto el tercer Evangelio como el libro de los Hechos han nacido de la pluma del mismo autor. Así se ha creído desde antiguo y lo corroboran las investigaciones modernas por el análisis interno de ambos escritos. Tanto el Evangelio como el libro de los Hechos utilizan el mismo vocabulario, usan los mismos recursos literarios y comparten los mismos puntos de vista teológicos. De tal modo que podemos decir, sin temor a equivocarnos, que ambos libros constituyen un conjunto literario y teológico.

Otras cuestiones donde no se da tal consenso son las que se refieren al nombre de ese su autor, a su relación con Pablo y a si concibió sus dos libros como una sola obra, en dos tomos, desde el principio o, más bien, ambas obras tienen una unidad de hecho, pero no prevista por su autor desde el principio. Es decir, que el autor concibió primero el Evangelio y en un segundo momento compuso el libro de los Hechos inspirándose para ello en el Evangelio que pocos años antes había concluido.

2 Buenas introducciones a los aspectos literarios de la doble obra lucana pueden encontrarse en: S. Guijarro, Los cuatro Evangelios (Salamanca, 2010); H. Koster, Introducción al Nuevo Testamento (Salamanca, 1988); W. Marxsen, Introducción al Nuevo Testamento (Salamanca, 1983); A. Wikenhauser y J. Schmid, Introducción al N. T. (Barcelona, 1978); A. George y P. Grelot, Introducción crítica al N. T. (Barcelona, 1983); P. Vielhauer, Historia de la literatura cristiana primitiva (Salamanca, 2003). Comentarios al tercer evangelio en: F. Bovon, El Evangelio según San Lucas, vols. I-IV (Salamanca, 1995-2010); J. A. Fitzmyer, El Evangelio según Lucas, vols. I-III (Madrid, 1986-1987 y IV 2005); y comentarios al libro de los Hechos en: J. Roloff, Hechos de los apóstoles (Madrid, 1984); J. A. Fitzmyer, Los Hechos de los Apóstoles, vols. I-II (Madrid, 2003). 
Respecto a esta última cuestión, comparto la opinión de muchos estudiosos según la cual el autor escribió primero el Evangelio y luego el libro de los Hechos de los Apóstoles, sin haberlos concebido desde el principio como una única obra en dos tomos. Que el libro de los Hechos fue escrito después del Evangelio lo reconoce el mismo autor en su prólogo. Me parece más probable que el autor no se planteara desde el principio escribir la doble obra lucana sino que en un primer momento pensó en escribir únicamente su Evangelio al modo de los otros evangelistas que le habían precedido -al menos, Marcos y Mateo- con la intención de componer un texto lingüística, estilística y teológicamente más asequible para las comunidades paulinas, de cultura predominantemente helenística, y en un segundo momento, a la vista del éxito alcanzado por su primera obra y quizá animado por algunos miembros de las comunidades a las que había dirigido su evangelio, pensó en continuar su primera obra con un segundo libro para exponer cómo lo que se había iniciado en Judea -para Lucas Galilea es Judea (cf. Lc 4,44)- pasando por Samaría llegó a los confines de la tierra (Hch 1,8).

Dada la estrecha relación entre los dos libros lo más probable es que no pasara mucho tiempo entre uno y otro. Puesto que Lucas utilizó el evangelio de Marcos, hubo de componer su evangelio después del año 70. Hacia el año 150, Marción considera que Lucas es el único verdadero evangelio, lo que indica que para esa fecha ya estaba muy difundido. En consecuencia, podemos situarlo entre el año 80 y el año 140. El reinado del emperador Nerva (96-98), que rehabilitó a los judíos y no desató persecución alguna contra los cristianos, rectificando la política de su antecesor Domiciano, es un buen momento para que Lucas compusiera su obra.

En cuanto a la personalidad del autor, del texto mismo del Evangelio y del libro de los Hechos podemos deducir que su autor es una persona culta, buen conocedor del griego, el más elegante del N. T. junto con el de la Carta a los Hebreos, educado en la retórica griega como Pablo y muy familiarizado con la traducción griega del A. T. hebreo, a la que tiene gran aprecio e imita con frecuencia. Podemos suponer que es un discípulo de origen judío con buena formación helenística, o quizá es el único autor no judío del N. T. a tenor de lo dicho en Colosenses 4,11.14, con acusada sensibilidad por la historia general, con autoridad suficiente en su comunidad para reinterpretar la historia de Jesús y persona capaz de reunir, a partir de los recuerdos y testimonios de la primera 
generación, el material necesario sobre Jesús y sobre la Iglesia primitiva para componer sus dos obras.

Estos dos libros, como el resto de los evangelios canónicos, son anónimos, es decir, no fueron firmados por su autor. Pero desde mediados del siglo II comienza a aparecer en los manuscritos la atribución a Lucas de este tercer Evangelio. Ya a mediados del s. II el papiro 53, después de este Evangelio dice «Evangelio según Lucas». El testimonio explícito más antiguo es probablemente el de Ireneo (Adv Haer. 3,1,1 y $3,14,1)$. También el Canon de Muratori lo atribuye a Lucas y el prólogo antimarcionita dice: «Lucas nació en Antioquía de Siria. Fue médico de profesión, discípulo de los apóstoles y, más tarde, compañero de Pablo hasta que éste sufrió el martirio. Aunque ya existían relatos evangélicos, uno según Mateo, compuesto en Judea, y otro según Marcos, escrito en Italia, Lucas, impulsado por el Espíritu Santo, compuso esta narración evangélica en alguna parte de la región de Acaya».

Aunque el citado prólogo antimarcionita dice que Lucas compuso su evangelio en Acaya, san Ireneo parece suponer que lo hizo en Roma. Estudiosos modernos han postulado Éfeso como el lugar donde el tercer evangelio vio la luz. No sabemos, pues, con certeza dónde se escribió, pero estamos seguros de que fue compuesto fuera de Palestina para alimentar la fe de las comunidades que habían tenido su origen en la misión paulina de la que Lucas parece haber formado parte.

La cuestión acerca de si el autor del tercer evangelio se llamaba Lucas, quizá deba responderse afirmativamente. No hay ninguna razón para suponer que se atribuyera el tercer Evangelio a un personaje sin mucha relevancia, como de hecho tuvo que ser Lucas, para la Iglesia de la primera hora y también, al menos, para nuestro conocimiento, aunque una cierta autoridad hubo de tener en sus comunidades. Así como es razonable pensar que los evangelios de Mateo y Juan se atribuyeran a estos dos discípulos directos de Jesús precisamente para reconocerlos autoridad apostólica, no hay ninguna razón para hacer lo mismo con Marcos y Lucas. Son personajes de relevancia secundaria en la Iglesia primitiva de modo que la autoridad apostólica de sus evangelios se reconoce vinculándolos respectivamente con Pedro y con Pablo.

Sin embargo, la vinculación de Lucas con Pablo no hubo de ser tan estrecha ni pudo tener tanta duración como tradicionalmente se ha venido considerando. Si Lucas fue compañero de Pablo lo tuvo que ser solamente al final. En el análisis interno la conexión de este compañero 
de Pablo con la obra lucana se basa en las cuatro secciones «nosotros» (cf. Hch 16,10-17; 20,5-15; 21,1-8; 27,1-28,16), que denotan un conocimiento bastante cercano de la actividad viajera por mar del apóstol. Sin embargo, estas secciones «nosotros», pueden soportar otras interpretaciones distintas de las de reflejar que Lucas viaja con Pablo. Pueden provenir de una especie de diario de viaje de quien realmente acompañaba a Pablo, utilizado luego como fuente por Lucas para el libro de los Hechos, o pueden deberse sencillamente a la maestría narrativa de Lucas.

Todas las noticias que nos han llegado sobre la vinculación de Lucas con Pablo se encuentran en el N. T. y más tarde las repiten otros autores. Son las siguientes: Col 4,14 donde Lucas aparece como «el querido médico» en los saludos finales de la carta; 2Tim 4,11 donde también al final de la carta el autor pone en boca de Pablo que «solo Lucas está conmigo" y Flm 24 donde Lucas es citado entre los colaboradores de Pablo. De las tres citadas, solo esta última carta es reconocida en la actualidad como auténtica de Pablo. Aunque la carta a Filemón incluye a Lucas entre los colaboradores de Pablo, sin embargo, es preciso reconocer que Lucas en Hechos tiene un pensamiento teológico propio y divergente del de Pablo -solo en Hch 13,38 habla Lucas de la justificación en un sentido paulino-y muchas de sus noticias históricas no casan con las cartas de Pablo. Por poner un ejemplo, parece que Lucas no sabe que Pablo ha enviado cartas a sus comunidades o si lo supo nunca lo mencionó. De modo que si Lucas fue compañero de Pablo hubo de serlo únicamente al final de la vida del apóstol.

\section{LUCAS Y EL JUDAÍSMO}

El ambiente de Lucas es el Imperio romano, al contrario que Mateo, que está inmerso en el mundo judío. En el tercer Evangelio se halla presente la herencia judía, pero de modo mucho más distante que en Mateo y Marcos. Lucas ve el judaísmo como la religión de origen del cristianismo. Pero ahora el evangelio se ofrece a todos por igual, aunque haya sido predicado "primero a los judíos, después a los griegos» (Hch 13,46, cf. Rom 1,16; 2,9-10). Da la impresión de que Lucas considera la herencia judía un elemento del pasado que ha quedado ya clausurado $\mathrm{y}$, desde luego, irrelevante para sus comunidades en el momento en que 
Lucas escribe, o con una relevancia meramente literaria e histórica. Por eso no encontramos en Lucas la discusión sobre los alimentos como en Marcos y la polémica antifarisea carece de la relevancia que recibe en Mateo. Quizá porque ya pertenece a la historia y por no ser significativa para sus comunidades tampoco necesita ser polémica. Sin embargo, Lucas aprecia la herencia judía. Es el evangelio que tiene una mirada más positiva sobre el templo de Jerusalén que, obviamente, cuando Lucas escribe ya no existe.

Con Jesucristo se inicia una etapa nueva en la historia de la salvación. Esa historia tiene una prehistoria que es el Antiguo Testamento. Tanto el Evangelio como el libro de los Hechos vive sin conflicto la historia del judaísmo. A esta ausencia de conflicto contribuye sin duda la lejanía tanto geográfica como temporal de las comunidades de Lucas, pero se basa, sobre todo, en que el judaísmo es historia pasada para los cristianos. Los judíos son los antepasados de la Iglesia, de la que la tradición bíblica veterotestamentaria da testimonio. Podemos verlo en la parábola de las minas (Lc 19,11-27). Después de quitar la mina al siervo que no la había hecho producir para dársela a quien tenía diez minas el hombre noble y dueño de las minas añadió: "Os digo: al que tiene se le dará, pero al que no tiene se le quitará hasta lo que tiene. Y en cuanto a esos enemigos míos, que no querían que llegase a reinar sobre ellos, traedlos acá y degolladlos en mi presencia». La alusión al judaísmo es clara. Algunos han querido ver en este pasaje un cierto antisemitismo lucano, pero probablemente haya que entenderlo, más bien, en el sentido de que el judaísmo tuvo su momento en la historia de la salvación, pero ya no lo tiene, pues ha dado paso a la Iglesia. La referencia al final del pueblo judío como entidad en la que se hallaba presente la sekináh divina tras la dispersión del año 70 me parece clara. De ahí que Lucas utilice e imite el lenguaje de Septuaginta especialmente en los relatos de la infancia y en los primeros capítulos del libro de los Hechos. Es esta una imitación literaria que refleja cómo empezaron las cosas pero que ahora ya han cambiado.

\section{LUCAS Y EL PUEBLO SAMARITANO}

Lucas concede también una cierta relevancia al pueblo samaritano como más tarde hará también el evangelio de Juan. Esta relevancia es 
explícita en el libro de los Hechos, pues el anuncio de la fe ha de pasar por Samaría para llegar a los confines de la tierra (Hch 1,8) lo que ocurre por mano de Felipe (Hch 8, 1b-25) y queda reflejada también en algunos pasajes del Evangelio. El relato del buen samaritano (Lc 10,25-37), al que luego me volveré a referir, no solo nos habla de la misericordia, sino que el hecho de que el protagonista sea samaritano subraya que la misericordia ha de ser universal transcendiendo las fronteras étnicas o nacionales. También el leproso agradecido es samaritano (Lc 17,16) lo que nos habla de que la acogida de la salvación es universal. La prohibición de Jesús a sus discípulos de ir a tierra de paganos y de no entrar en las ciudades de samaritanos que encontramos en Mateo (Mt 10,5) y que probablemente recoge la conciencia de Jesús de circunscribir el anuncio del reino durante su vida terrenal a las ovejas perdidas de la casa de Israel, está ausente en Lucas. El rechazo de los mensajeros enviados por Jesús en una aldea de Samaría, que encontramos únicamente en Lucas (9,51-56) al comienzo del viaje a Jerusalén, no dice nada en contra de incluir a los samaritanos en la universalidad de la salvación, pues es la ocasión para que Santiago y Juan pregunten a Jesús si deben pedir que baje fuego del cielo que acabe con ellos, lo que concluye con la desautorización de Jesús sobre tal propuesta.

\section{LUCAS Y LOS PAGANOS}

Lucas escribe, pues, para comunidades formadas mayoritariamente por cristianos provenientes del paganismo. Por tanto, no siente la necesidad de legitimar que los paganos sean cristianos, como se deja ver en algunas de las cartas de Pablo. Lucas narra la historia de cómo el cristianismo se ha abierto a los paganos, historia que se debe a la acción de Dios y ha sido dirigida por Él. La misión confiada por Jesús a los Doce (Lc 9,1-6) se amplía en la misión de los setenta y dos discípulos, episodio propio de Lucas, en referencia a los pueblos no judíos (Lc 10,1-20). En el Evangelio nos cuenta la apertura de Jesús a los paganos que se acercan a él, como podemos ver en el episodio del centurión (Lc 7,1-11) y en el libro de los Hechos aparece claro cómo es la acción de Dios quien lleva a los paganos a la fe. La llegada del mensaje de salvación a Antioquía se debe a la acción de Dios (Hch 11,19-30). En el caso del ministro de Candaces, reina de Etiopía (Hch 8,26-40), es el ángel 
del Señor quien le indica a Felipe el camino que debe seguir para hacer posible el encuentro con el etíope y luego es el Espíritu Santo el que le manda "acercarse y pegarse a la carroza». Algo parecido ocurre en el episodio del centurión Cornelio (Hch 10,1-11). Ni Cornelio ni Pedro tienen intención de que Cornelio llegue a la fe ni conocen el resultado de las acciones que emprenden. Es el Espíritu Santo quien les conduce y quien, al final, resuelve la situación bajando sobre los que escuchaban la Palabra. Podemos decir, pues, que la perspectiva universalista atraviesa tanto el Evangelio como el libro de los Hechos, cuyo pasaje central literaria y teológicamente es el relato de la asamblea de Jerusalén (Hch 15), donde la Iglesia decide la admisión de los paganos a la fe en plano de igualdad con los judíos, es decir, sin que los gentiles deban primero hacerse judíos para heredar las promesas. Para Lucas la misión a los gentiles realizada por Pablo tiene lugar cuando la Iglesia reunida en Jerusalén toma autoritativamente la decisión de admitir a los paganos sin exigirles la circuncisión y el consiguiente sometimiento a la Ley judía, pero Lucas no puede evitar por completo la narración de que esa apertura a los paganos se debió de hecho a la predicación carismática de algunos misioneros de la primitiva Iglesia, entre los que Bernabé y Pablo fueron quizá los más importantes. El anuncio a los paganos históricamente tuvo lugar antes de la decisión de la Asamblea de Jerusalén.

\section{LUCAS Y EL MUNDO}

El protagonista tanto del Evangelio como del libro de los Hechos es el Espíritu Santo. El Espíritu Santo, solo en Lucas en forma de paloma, se posa sobre Jesús en el bautismo y le conduce a lo largo de toda su vida. Tras la ascensión, el Espíritu Santo desciende sobre la Iglesia en pentecostés y guía su desarrollo y expansión. El Espíritu, que es el Espíritu de Jesús, ha sido derramado al mundo. De modo que la acción del Espíritu ocurre en el mundo sin estar sujeto a las limitaciones inherentes a la condición creatural del mundo. El mismo Verbo de Dios, al asumir nuestra condición creatural, quedó limitado, pues hubo de hacerse hombre en un pueblo concreto, hubo de hablar una lengua determinada, pertenecer a una cultura, a una clase social y fue varón y no mujer, etc. Pero tras la resurrección el Espíritu de Dios, que es el 
Espíritu de Jesús, se derramó sobre el mundo superando esas limitaciones. Por eso en el día de pentecostés todos los reunidos en Jerusalén oyen a los apóstoles hablar en su propia lengua (cf. Hch 2,7-11). La encarnación limita de alguna manera el absoluto de Dios mientras que la acción del Espíritu no está limitada a lo concreto como lo está la actuación del Hijo.

\section{LUCAS Y LA HISTORIA UNIVERSAL}

Una de las características de Lucas tanto en el Evangelio como en el libro de los Hechos es insertar, respectivamente, la historia de Jesús y el desarrollo de la Iglesia primitiva en la historia universal. Quizá deriva de aquí la fama de historiador que la tradición le ha concedido a Lucas, cuando de hecho todos los evangelistas son historiadores. Lucas lleva la genealogía de Jesús hasta Adán, uniéndolo así a toda la humanidad. Por el contrario, Mateo solo la lleva hasta Abraham y la centra en David, vinculando a Jesús más bien con el pueblo de Israel. Sin embargo, la dimensión universal tampoco está ausente de Mateo ya que las cuatro mujeres que incluye en su genealogía patriarcal, por ser extranjeras o, al menos, tenidas por tales, dan a la genealogía de Jesús su dimensión universal.

Igualmente, el comienzo de la vida pública de Jesús (Lc 3,1-2) no solo está ubicado en la historia judía con la mención de Anás y Caifás y en el Imperio romano con la cita del emperador Tiberio y el gobernador Poncio Pilato, sino que el autor menciona también a los tetrarcas de Galilea y las regiones limítrofes de Iturea, Traconítida y Abilene.

H. Conzelmann tituló su estudio del Evangelio «El centro de la historia. La Teología de Lucas»³. La primera parte sería el A. T., el Evangelio sería el centro de la historia y la tercera y última parte sería la vida de la Iglesia que se inicia en Hechos. Estudiosos más recientes piensan que es mejor pensar la historia según Lucas dividida en dos partes: el tiempo de la promesa (A. T.) y el tiempo del cumplimiento. Y este dividido en dos momentos: el tiempo de Jesús y el tiempo de los testigos, que a su vez se divide en el tiempo de los testigos oculares y el tiem-

\footnotetext{
3 Madrid, 1974.
} 
po de la generación presente ${ }^{4}$ (Bovon). El plan del libro de los Hechos es narrar el testimonio sobre el misterio cristiano, que partiendo de Jerusalén y pasando por Samaría llega hasta los confines de la tierra (Hch 1,8). En una palabra, el acontecimiento de Jesucristo y la fe cristiana, que partió de él, es un fenómeno que se desarrolla en la historia universal.

\section{EL UNIVERSALISMO SOCIAL}

Pero el universalismo de la obra lucana no se limita a superar los particularismos étnicos o nacionales. El universalismo de Lucas se extiende también a las clases sociales. En el Evangelio de Lucas, Jesús se distingue, quizá de modo más claro que en los otros evangelios, por la misericordia, la compasión y el perdón, dirigido especialmente a los pobres, marginados y pecadores. Muchas de las parábolas propias de Lucas y de sus relatos ejemplares, como el administrador avispado, el buen samaritano o el rico banqueteador, están centradas en la solidaridad, la misericordia y el perdón.

Lucas piensa que puede haber una correcta utilización de los bienes de este mundo. Es necesario hacerse amigos con los bienes de este mundo para que cuando lleguen a faltar los que tienen bienes sean recibidos en las moradas eternas (Lc 16,9) de modo que para los cristianos es imprescindible la solidaridad y la ayuda mutua. En el tema de las riquezas, Jesús fue mucho más radical de lo que los cristianos hemos sido a lo largo de la historia y probablemente de lo que podamos ser. En lo evangelios de Marcos y Mateo con los bienes de este mundo solo se puede hacer una cosa que es dejarlos. En Lucas, por el contrario, los bienes pueden ser bien utilizados. Se ha dicho que Lucas es el evangelista de los pobres, pues en él encontramos que los bienes de este mundo pueden ser correctamente utilizados si se usan de modo solidario y practicando la caridad con los necesitados. Por eso se ha dicho también que Lucas es el evangelista de los ricos. Pues los ricos pueden, gracias a la solidaridad, la justicia y la caridad, ser recibidos en las moradas eternas, pero sin que la radicalidad de Jesús los obligue

4 F. Bovon, El Evangelio según san Lucas, 1-4 (Salamanca, 1995-2010). 
a dejarlos. De modo que la universalidad de Lucas se extiende también a las clases sociales.

\section{LUCAS Y LAS MUJERES}

De modo coherente con el interés de Lucas por los que importan menos, sus obras prestan atención especial al protagonismo de las mujeres: María, la madre del Señor protagoniza los relatos de la infancia junto con Isabel, la madre del Bautista, al contrario que el evangelio de Mateo donde el personaje principal es José. Lucas es quien más noticias nos da de las seguidoras de Jesús en el evangelio (Lc 8,1-3; 23,27-31 y 24,10), al tiempo que presenta episodios propios protagonizados por mujeres: viuda de Naín (Lc 7,11-17), Marta y María (Lc 10,38-42), la mujer tullida $(13,10-17)$, parábola de la moneda perdida (Lc 15,8-10), el juez y la viuda $(18,1-8)$. Muy probablemente esto se debe no solo a la sensibilidad de Lucas sino a la relevancia social que las mujeres tenían en la cultura grecorromana, muy superior a la consideración que se les concedía en el ámbito judío. Y seguramente también al hecho de la relevancia que tuvieron las mujeres en el equipo evangelizador de Pablo. Tanto en el libro de los Hechos como en las cartas de Pablo son numerosos los nombres de mujeres que aparecen como colaboradoras de Pablo: Febe, diácono de la iglesia de Céncreas (Rom 16,1), Prisca -Priscila en el libro de los Hechos- que junto con su esposo Áquila son denominados por Pablo «mis colaboradores en la obra de Cristo Jesús» (Rom 16,3), María, «que tanto ha trabajado por vosotros» (Rom 16,6), Junia que junto con su marido Andrónico, paisanos de Pablo y compañeros de prisión, «descuellan entre los apóstoles y fueron cristianos antes que yo» (Rom 16,7), Trifena y Trifosa "que han trabajado por el Señor» (Rom 16,12), Nerea y su hermana Olimpa (Rom 16,15), por citar solo a las que aparecen en la carta a los Romanos, pero se podrían añadir otros nombres como el de Cloé, en Corinto, Lidia la comerciante en púrpura de Tiatira, que es la primera cristiana europea de quien tenemos noticia (Hch 16,14-15), o Evodia y Síntique en Filipos. De modo que la universalidad de Lucas se refiere no solo a las etnias sino también a las clases sociales y a la diferenciación de la humanidad por sexo o género. 


\section{CONCLUSIÓN}

El tiempo de la Iglesia es el tiempo del testimonio. Así se lo indica Jesús al despedirse de sus discípulos en la ascensión "seréis mis testigos en Jerusalén, Judea y Samaría y hasta los confines del mundo», frase que establece el plan del libro de los Hechos. Ese testimonio es, pues, universal y se realiza en la fraternidad -«la multitud de los creyentes tenía un alma y un corazón»- y frecuentemente en la persecución. El autor va relatando las persecuciones que tienen que sufrir los testigos hasta culminar en la persecución que sufre Pablo. Este es acusado de haber introducido unos griegos en el templo de Jerusalén, «profanando este santo lugar» (Hch 21,28). Estoy seguro de que Pablo no transgredió la prohibición de introducir a los no judíos en el templo y, sin embargo, la acusación era verdadera, porque Pablo, el apóstol de los gentiles, nos introdujo a todos nosotros en el templo, no en el templo físico de Jerusalén, sino en el templo celestial donde Dios tiene su morada, al habernos considerado herederos de las promesas al pueblo de Israel.

Los cristianos cada vez que celebramos la Eucaristía, en la plegaría eucarística, invocamos dos veces al Espíritu Santo. Pedimos primero que el Espíritu Santo transforme los dones de pan y vino que hemos presentado en el Cuerpo y la Sangre del Señor y una vez que el Cuerpo y la Sangre del Señor se hallan presentes en el altar pedimos que el Espíritu Santo nos incorpore al Cuerpo del Señor para ofrecernos con Él en su mismo sacrificio. Al formar parte del Cuerpo del Señor nos convertimos también en miembros unos de otros. Todos los cristianos somos miembros del Cuerpo de Cristo y por eso somos miembros unos de otros. Y los que no son cristianos están llamados a serlo porque "Dios quiere que todos los hombres se salven y lleguen al conocimiento de la verdad» (1Tim 2,4) o incluso forman ya parte del Cuerpo de Cristo más allá de la Iglesia visible, aunque ni ellos ni nosotros lo sepamos. Según la dinámica del indicativo y el imperativo, tan presente en Pablo, que nos invita a ser lo que somos, los cristianos hemos de tener una mentalidad universalista, que considera a todos los hombres uno en Cristo Jesús y hemos de obrar en consecuencia. De modo que los cristianos estamos llamados no a poner fronteras entre los hombres por diferencias de raza, clase social, género o cultura, sino a derribar esas fronteras o a hacerlas irrelevantes allá donde todavía existan. 


\section{BIBLIOGRAFÍA}

Bovon, F. El Evangelio según San Lucas. 4 vols. Salamanca, 1995-2010. Busto, José Ramón. "Rut y Jonás contra Esdras". Sal Terrae 102, n. 112 (2014): 653-664.

Conzelmann, H. El centro de la historia. La Teología de Lucas. Madrid, 1974.

Fitzmyer, J. A. El Evangelio según Lucas. 3 vols. Madrid, 1986-1987 y IV 2005.

-. Los Hechos de los Apóstoles. 2 vols. Madrid, 2003.

George A., y P. Grelot. Introducción crítica al N. T. Barcelona, 1983.

Guijarro, S. Los cuatro Evangelios. Salamanca, 2010.

Koster, H. Introducción al Nuevo Testamento. Salamanca, 1988.

Marxsen, W. Introducción al Nuevo Testamento. Salamanca, 1983.

Roloff, J. Hechos de los apóstoles. Madrid, 1984.

Vielhauer, P. Historia de la literatura cristiana primitiva. Salamanca, 2003.

Wikenhauser A., y J. Schmid. Introducción al N. T. Barcelona, 1978. 